\title{
Some Flavors of Russian Neocolonialism in Central Asia
}

\author{
Alexandru Ioan Gherasim \\ Corvinus University of Budapest, Budapest, Hungary \\ ioanalexandrugherasim@gmail.com
}

\begin{abstract}
The term "neo-colonialism" is attributed to Kwame Nkrumah, who considers it to be the last stage of imperialism and means "the exercise of power but not of responsibility by the powerful exploiters without alternatives for the dominated". An introspection at the level of the specialized literature allows to find that there are many definitions of this concept, being able to speak even about a series of regional versions of the term (African, Asian or Latin American). Research by many analysts has revealed the deep vulnerabilities of the state of fact that can be categorized as a neo-colonial type. In this paper we start from the hypothesis that the states of Central Asia are in a unique situation because it is not possible to speak of complete independence if most of their resources are still used in the interest and development of those who are in the vicinity of the region or at distances greater than this. Throughout this paper, sustainable arguments are made in support of the idea that some factual states attributable to neocolonialism can be attached to the relations that Russia has today with the former components of the USSR that have declared their autonomy and are developing as independently as possible. The analysis is focused on aspects such as: the great difficulties encountered by the states in this region during the processes of capital accumulation, endowment with modern technologies and the approximation of the most sustainable managerial practices; the almost complete repatriation of the profits obtained by the foreign investors in these regions which are so deprived of important own sources of financing, determining them to remain dependent on the foreign investors and vulnerable to the seismic or asymmetric economic shocks; the special sensitivity of the external debt vector used with great ability by both international financial institutions and the commercial banking system in developed countries to radically influence macroeconomic and sectoral policy decisions; the continued use of these states as a field of confrontation between the great powers.
\end{abstract}

Keywords: neo-colonialism; Central Asia; geo-political and geo-economic equilibrium; paradigm shift; asymmetric economic shocks; confrontation.

\section{Introduction}

The subject of colonialism, which is linked to a rather long stage in the evolution of modern, but also pre-modern civilization, continues to arouse the interest of the entire scientific spectrum, manifesting the more the concept has become enriched with the neo- and post- prefixes, being approached by a great variety of theorists and historians of the theory of international relations (be they economists or political scientists, sociologists and anthropologists, moral or cultural philosophers). Moreover, followers of all currents / doctrines / ideologies in the sphere of international relations have identified typologies of the phenomenon or observed the cohabitation of polemical approaches: deontological vs. utilitarian (speaking in terms of individual natural rights or collective costs and benefits), vindictive vs. justifications (demanding historical reparations for otherwise indelible sins or excusing sacrifices in the name of progress).

A "folkloric" definition of the concept (beyond the academic ones that we will analyse from different perspectives) speaks of "a practice of domination", which implies "subjugating one people with another", but this "positive" vision does not necessarily surprise subtlety and the sensitivity of the "normative" judgments / interrogations to which such a reality lends itself unwillingly. Is the inter-spatial domination of those who hold the key of truth / good / beautiful, of civilization, over inter-temporal condemnable barbarism? Is not the history of civilization the

DOI: $10.2478 /$ picbe-2020-0044, pp. 464-473, ISSN 2558-9652| Proceedings of the $14^{\text {th }}$ International Conference on Business

Excellence 2020 
story of the "domination" of the superior over the inferior (moral or material), in the name of the diachronic enlargement of the multitude of the former to the detriment of the other? But what exactly does superiority, progress, civilization mean? Which definition (or intuition) is better than all "products" / "consumed" in various "libraries" or " diplomatic offices"?

The colonial phenomenon has been supported by a variety of means, some of them quite elitist in nature and manner of presentation. Strong doctrinal lines appeared that aimed to justify the factual states and to accredit the idea that these types of social relations are correct and perpetual, witnessed the breakdown of social sciences from sub-fields that were included in the educational programs of the educational environment, pretentious exhibitions were organized and with great civic impact, books were published and scientific magazines were published with the object of this phenomenon, numerous songs were launched and works of art were created with this theme, created professional and scientific associations of those who worked in the colonies and had experiences considered useful for dissemination.

Throughout this paper, sustainable arguments are made in support of the idea that some factual states attributable to neo-colonialism can be attached to the relations that Russia has today with the former components of the USSR that have declared their autonomy and are developing as independently as possible. The analysis is focused on aspects such as: the great difficulties encountered by the states in this region during the processes of capital accumulation, endowment with modern technologies and the approximation of the most sustainable managerial practices; the almost complete repatriation of the profits obtained by the foreign investors in these regions which are so deprived of important own sources of financing, determining them to remain dependent on the foreign investors and vulnerable to the seismic or asymmetric economic shocks; the special sensitivity of the external debt vector used with great ability by both international financial institutions and the commercial banking system in developed countries to radically influence macroeconomic and sectoral policy decisions; the continued use of these states as a field of confrontation between the great powers

\section{Some reflections on the idea of neo-colonialism}

The term neo-colonialism is attributed to the well-known Pan-Africanist leader Kwame Nkrumah, who, in a Marxist sense, considered it to be the last stage of imperialism, in its acceptance meaning "the exercise of power, but not of responsibility by the powerful and exploitative. without alternatives for the dominated ones,, (Northrop, D. 2012). The perception of neo-colonialism is very close to that credited to Kant and later to Marx, this stage being one in which the features of imperialism are generalized, seen as the most advanced stage of capitalism, as a dominant mode of production.

The defining realities for neo-colonialism can no longer be understood if one does not resort to a matrix-type approach in which highly contextual cultures are juxtaposed with weakly contextual ones, behaviors considered to be rational with those that are difficult to frame from this point of view, perceptions about stability with those about instability, order with disorder, integration with disintegration, etc. There is no lack of analytical utility nor the interfering radiography of the exercise of various forms of authority with the voluntary conformation, or of the intentional and aspirational plan. An interesting contribution to the analysis of post-colonial realities is made by Gayatri (1988) who raises the question of the right of the dominated one to be able to express himself freely and to dialogue with the one who wants to have it in his sphere of influence. The key terms of the analysis are transparency and direct dialogue, directly by various 
categories of intermediaries. The conclusion reached is that, if one maintains a kind of relationship dominated by the existing force ratio, one cannot discuss transparency or authenticity.

The theory regarding the post-colonial realities gains relevance if one uses more doctrinal perspectives, being necessary to approach the problem in both the standard register for the political or economic sciences, as well as in the relevant one for the social and humanities sciences. The entire complexity of post-colonialist realities cannot be understood unless one uses post structuralism, realism, institutionalism, neo-functionalism. The key terms that more and more analysts invite us to consider are: hybridity, diaspora, representation, narrative, alterity, multiplicity and knowledge/power. In order to have an image as relevant as possible to the phenomenon of neo-colonialism, the works of authors such as Williams and Chrisman (1993) and Ashcroft (2000). This author's contributions focuses on efforts to address three powerful antinomies in postcolonial theory, regarding (a) the agency of dominated groups, whether it determines their own fate, (b) the power of the West, if Western paradigms are inevitable, and (c) the purpose of liberation and when and how postcoloniality could ever end. A special attention is paid to the tensions between postcoloniality theory and postmodernism and the efforts to relate postcoloniality and globalization, authors arguing against portraying globalization as the end of postcoloniality, in favor of representing the two as intrinsically linked.

Thus, the postcolonial theory recognizes and recovers the continuous significance of the colonized peoples, decanting them from the dominant Western epistemologies, philosophies and practices and taken as absolute references. Postcolonial theorists do not claim that colonialism was experienced in the same way under different regimes, while admitting that today colonialism operates in very different ways from its previous configurations. However, while paying attention to the details of specific contexts, they admit that it is important to consider and correct the persistence with which, in the "dominant discourse", Europeans are still presented as "civilized", "progressive" and "Legal" against native populations "barbaric", "static" and "lawless". Ironically, the very process of self-determination practiced by the colonized peoples themselves requires the adoption of European knowledge, including concepts such as "progress", "development", "individualism" and what it means to be human. It also implies the use of Western forms of government, state-building and, most importantly, of all, legislation. Thus, according to a postcolonial perspective, "all statements about freedom and self-awareness require elements of mimicry and voyeurism." (Darian-Smith, E. 2015). Research on this thematic area has revealed that neo-colonial vulnerabilities can take various forms, such as:

- The great difficulties encountered during the processes of capital accumulation, endowment with modern technologies and the approximation of the most sustainable managerial practices. Some narrow places should also look for the generous programs of international economic institutions (IMF, World Bank Group, etc.), which did not mitigate these gaps, but even tolerated them and helped to amplify them.

- The full repatriation of the profits obtained by the foreign investors in these regions, which deprives these states of important own sources of financing, determining them to remain dependent on the foreign investors and vulnerable to the symmetrical or asymmetric economic shocks.

- External debt vector - very sensitive and used with great ability by both international financial institutions and the commercial banking system in developed countries to radically influence macroeconomic and sectoral policy decisions. 
- The continued use of these states as a field of confrontation between the great powers. If during the so-called Cold War period, the confrontation was between the US and USSR, after 1990 in the geopolitical and geo-economic equation a new global player, namely China, changed, substantially changing the rules of the game.

\section{Positioning of the Russian Federation in relation to the neo-colonialist challenges}

Although he it has become a real truism that this great power has constantly promoted colonialism, in the discussions with the representatives of Russia the almost routine answer given by them is that there is no talk of neo-colonialism in a non-colonial country. The complex and, to a large extent, unpredictable transformations that took place in a relatively short period of time in the former Soviet space made it very difficult to anticipate the level at which political and economic stability could be placed. For both diplomatic and academic cancellations, the subject of democratization of political regimes in this geographical area has become very attractive. Against this background, one of the analysts of these realities (Hale, H. 2005) claims that these transformations are not some linear ones, but cyclical, and the rivalries that can be identified in all the states of the region are not related to the maturation of a local civil society, but to autocratic structures. The same author considers that "... we should study the post-Soviet developments and classify them not as democratization / authorization, but as institutionalization / a-institutionalization, competitiveness / non-competitiveness, and stabilization / destabilization." It became compulsory for all state-owned entities resulting from the dismantling of the USSR, that it had to enter a race at the end of which a new national identity project was to be. The essence of this belief can be found in the following approach: "No nation is likely to survive, let alone preserve its culture, without a clear understanding of its national idea or a certain vision of its prospects. This makes society and the people vulnerable". (Moiseev, N.N. 1999) In order to achieve this outline, it becomes necessary to develop and operationalize a set of strategies, the most important being: the national development strategy; strategic positioning or repositioning strategy; national security strategy.

As Sergei Soloviev metaphorically described the Russian realities, as early as 1840, "the history of Russia is the history of a country that colonizes itself." (Etkind, A. 2015) It is surprising the fervor with which all Russian intellectuals firmly reject the idea that their country was a colonial power and that it still has such behavior. Any attempt by Western researchers to make comparisons between the political, military or economic presence of England or France in certain regions of the globe and that of Russia in others is fought with virulence. The explanation of this attitude is related to the traditional perception of the terms of colonialism and neocolonialism, the belief that the representatives of the Russian academic environment have that these phenomena are related only to certain powers labeled as "colonial". Some researchers have shown that the longer an illiberal regime stays in power, the more time and resources it has to enhance all these tools. It cannot be said that this condition is not fully fulfilled by the dominant regime in Moscow, which has been in power for more than 20 years and there are signs that the period will continue to extend, without an acceptable prospect as to what is possible. change. The measures that can be taken are aimed at limiting the commercial flows, having as an objective Artificial Intelligence (AI) elements that allow biometric identification - the faces, the voice, the allure; imposing restrictions on public companies and authorities providing monitoring technologies, training programs, complex equipment to authoritarian regimes that practice human rights violations. State-of-the-art technologies, such as micro targeting or deep fakes, can 
enhance the ability of regimes that are not very friendly to the democratic values to manipulate their citizens by inducing actionable directions that are convenient for the rulers. As demonstrated even in the 2016 US election, by using micro targeting, governors can format the content of messages so that they become acceptable to smaller groups of individuals or even individuals taken separately. Demonstrations are already being made of autocratic governments that targeted individuals with cosmetic information that made them become supporters of certain political or diplomatic lines. Russia's concern is to maintain its imperial vocation by trying to reunify the former Soviet space in a specific way to the new geopolitical and geo-economic circumstances, but in accordance with the rules dictated by it. The problem is that most analysts mentioned the existence of this state of affairs but did not even explain it convincingly. In this approach the emphasis is placed on: the strength lines of the identity of these republics as being extracted from the inheritance of their belonging to the Tsarist Empire and to the USSR, which does not go well in these former republics as the main cause of the evil influence of the West. It is an unquestionable reality that, although they have gained independence from the metropolis, the new states resulting from the dismantling of the "Soviet empire" have not gained "real sovereignty" as some still depend heavily on economically and politically. and even culturally by the former center of political power. To this state of affairs also contributes the international political and economic system.

\section{Placing the Central Asia region in the equation of neo-colonialism promoted by Russia}

The reconsideration of Russia's foreign policy (Starr, F. Svante, C. (ed.) 2014) was made under the condition that, as a result of the steep increase in international prices for crude oil and natural gas, considerable financial resources were entered in the state treasury. With their help, the Russian authorities have slightly improved the standard of living of citizens and, on this background, it was considered appropriate to launch for public reflection the topic of the international role of the new state entity inheriting all foreign policy issues of the former Soviet Union. At the center of these efforts was placed an objective difficult to reject for the Russian citizens, the one to regain the historical honor and to preserve the integrity of the space on which this state considers that it has a duty to exert its influence. At first, the international community did not attach much importance to these signals, taking some time to notice the pitfalls of these internal and foreign policy messages. There were also some concrete moves on the geopolitical area. Russian troops launched a first attack on Georgia in 2008, in 2010 the pressure (it is expressly non-military) began on Kyrgyzstan, and in 2014 the first forms of involvement in Ukraine were felt.

It became obvious that some of the basic principles contained in the UN Charter (in particular respect for the territorial integrity of the states, the interference in the internal affairs of others, the sovereign equality) are no longer the basic foundations of a new geopolitical system prepared by the Russian authorities. The somewhat discreet and delayed reaction of the western chancellors was due to fears that a more radical position would appear to be embedded in the defining logic of the Cold War, which Western decision-makers were trying to detach. What became more and more obvious to the careful analysts of the movements that took place was the fact that, instead of being specific actions of the Russian administration, they were all clearly within the scope of an aggregate strategy that had both long-term goals. both internally and internationally. In other words, the aim was to rebuild a new Soviet Union - it is true, under other 
conditions and by other means, but still one in which the hegemon is the Russian Federation. It may be easy to point out that all the actions taken by Russia were not reactive (meant to respond to developments considered threatening by some neighbors), but proactive (they were part of an articulated approach pursued regardless of the stimuli that came from that region or beyond. Support for this idea are all attempts to influence political developments in the states of the region, annexation of Crimea, military support for all kinds of secessionist movements. Labeling the dismantling of the USSR as "a major geopolitical disaster of the twentieth century", Vladimir Putin announced the launch of the new type of economic integration on the former Soviet territory, but also the intention to propose to the partners the progress towards a full economic union and, in perspective, towards the most advanced stage of integration, that of political union.

It is worth mentioning the initial change of geopolitical paradigm at the level of the American decision-makers, who had begun after 1991 to no longer consider Russia an enemy, attaching to it the qualification of a possible credible partner. It helped to this perception also what the specialists in the scientific environment accredited as a change of dominant logic in the attitude of the decision makers in Moscow, placing them in the area well described by the deterministic doctrine. We can say that he fell into the trap according to which the actions taken by the Russians were characterized by: "being based on the historical argument; taking the European Union as an example of success; good intention and openness to sustainable and mutually beneficial partnerships" (Starr, F. Svante, C. (ed.) 2014). The imperial approach must be treated with the utmost care as history has fully demonstrated that no empire in the history of the world, when it reached its peak and entered decline, never recovered, no matter who and how it attempted it.

There are analysts who do not agree with this idea, invoking the fact that the Tsarist Empire is an exception to the rule, this "reincarnating" starting in 1920, through the USSR. This topic is not the subject of the present research, but it should be mentioned that things are not really simple and comparisons taken out of context do not lead to robust and scientifically relevant results. The two agglomerations of peoples operated under fundamentally different geopolitical and geo-economic circumstances, were influenced by particular factors and used coagulant binders of a particular type. Neither of these two experiences can be used as a benchmark (this seems to be understood by the Russian administration) for his efforts to reposition himself as a relevant actor in the future geopolitical picture. The new current politicalstrategic and economic landscape requires the use of other categories of partnerships, the most powerful becoming: energy resources, infra- and structural-info corridors, training programs, financial and capital flows, monetary policies, migrant flows. New geopolitical strategies must start from identifying " global public goods" (and by referring to them " global public worsts"), creating the foundations of partnerships that determine their production and balanced dissemination and the need for them. cooperation between governmental and non-governmental plans.

Some analysts have signaled an intelligent decoupling between the fervor with which one talks about the main strategic objective (that of the restoration of Greater Russia) and the almost total silence on the concrete ways by which to act to achieve this goal. It becomes increasingly clear the decoupling between the strategic and tactical plan, between their goals and means of serving them, between their good intentions and their commentable ways of concretizing them, between the public character of the strategic plans and the almost total secret in relation to the tactical ones. One thing that should worry (or at least worry about) is the massive centralization 
of the process, with only a small group of decision makers having access to the details being considered. This results in the subversivity of actions, an idea based on the fact that, if there were no goals to be hidden from others, the process would also involve non-state actors (corporate environment, NGOs, civil society) or sub-state (regions). It is also strange the excess of transparency, especially of the rhetorical type, which causes the political leader of Russia to organize more public conferences and to make more statements than his counterpart in the big democratic states.

The causes of this behavior are found in the specific institutional and democratic design of Russia. Despite some progress in the path of democracy and institutional transparency, this country still has a very large and influential government bureaucracy. As such, without placing the strategic dimension at the level of a single power center, the mechanism can become blocked, becoming inefficient. The leader of Moscow still considers the words democracy and disorder synonymous and conveys the message that Russia can only be led on the right path by "a strong hand". The worrying part is that Western leaders (European and American) believe that their Russian counterpart can be drawn from the "network" he has created and attracted in modern and mutually beneficial partnerships. As one of the analysts of this geo-political and geo-economic space emphasized (Mankoff, J. 2013) the problem of reintegration of the former Soviet space, initially at the level and with the help of economic mechanisms, was a constant one placed on the foreign policy agendas of the Moscow decision-makers, as they were not they have never reconciled with the idea of losing influence in a region that they considered permanently as belonging to them. Since 1995, the Kremlin authorities have decided that the issue of reintegration of the former Soviet space would become a strategic task of all government structures. As emphasized in the Russian media (Rossiyskhaya Gazeta. September 23, 19950, this strategic task had to be viewed as a binder of the integrity of the Russian Federation, a complex entity subject to numerous centrifugal movements. The forms designed to serve this desire are among the most diverse. Among the most popularized actions were those aimed at contributing to the emergence of integrationist groups, having especially economic and commercial objectives.

However, the attempts to relaunch intra-regional partnerships were not limited to the purely economic component. In the plan of military collaboration, since 1992, when the Tashkent Collective Security Treaty (CST) was laid, an arrangement that evolved into the Collective Security Treaty Organization (CSTO) (Carmen, A. and Gayoso, D. 2013), the message was transmitted that the great regional power wants to understand in some way namely the principles of public international law and that it follows a line that can be labeled as a neo-colonial type. It cannot be said that these outbreaks of foreign policy were kept purely on an intentional and unobtrusive level. Even top leaders in Moscow acknowledged, in 2008, after the military intervention in Georgia, that Russia has a number of special interests in certain states in the region, either in the form of a reconsideration of its geographical borders or in its sphere of influence. (Medvedev, D. 2008) It turned out a little later that, in Russian ruling circles, the imperial-type format is considered the only functional one for governing such a composite state and very large in surface area. A Russian analyst (Etkind, A. 2011) emphasized that "Empire is the main category of any strategic political analysis in the Russian language. Whenever we start to ponder a full-scale, long-term construction of the Russian state, we begin to think of empire and in terms of empire. Russians are inherently imperialists,, .

This type of attitude can be found textually in many foreign policy documents of the Russian administration. Thus, in 1999, the executive leadership in Moscow sent to the EU 
decision-making bodies a foreign policy document setting out some guidelines for the behavior of Russian decision-makers. This document shows the basic pillars of the foreign policy promoted by the Moscow administration, namely: " of a Euro-Asian state and largest country of the CIS. The development of partnership with the EU should contribute to consolidating Russia's role as the leading power in shaping a new system of interstate political and economic relations in the CIS area, 'and thus, Russia would oppose any attempts to ham-for economic integration in the CIS [that may be made by the EU], including through 'special relations' with individual CIS member states to the detriment of Russia's interest". (Strategiia Razvitiia Otnoshenii Rossiskoi Federatsii s Evropeiskim Soiuzom na Srednerochnuiu Perspectivu 2000-2010) The main message of this quote is that the Russian decision-makers have as a profession of faith and as a strategy of internal and foreign policy the behavior, at times undemocratic, even authoritarian, and the desire to create a regional integrationist block largely subordinated to their interests. What defines the constant attitude of this country is the requirement to behave really unhindered by its international obligations, and this behavior should be recognized and accepted not only by its neighbors, but by the entire international community. We can say that this state of affairs is in no way different from what it was in the 1920s, when Stalin emphasized that "Only two alternatives confront the border regions: Either they join forces with Russia and then be emancipated from imperialist oppression; or they join forces with the Entente, and then the yoke of imperialism is inevitable". (Stalin, I.V. 1942). The geopolitical developments of the last years confirm that the Kremlin continues to believe that the survival of the great international actor is possible only if its imperial structure is reconfigured, which can only be achieved to the detriment of the national sovereignty of other state entities and contrary to the principles of law. international. Some positions of Russian political leaders can only be worrying. Thus, in 2014, President Putin emphasized that "Kazakhstan was never a state before 1991". Such a public position is not a singular one but goes along the line supported by an important doctrinal line of the last decades. We find in many of the papers that dealt with this subject a series of arguments for and against this attitude, but also a series of analyzes that find the irony titled in the form "Russia makes its neighbors offers impossible to be rejected". This diplomatic rigidity, however, also expresses a state of outrage among Russian decision-makers, who have no patience, nor the diplomatic means with which to become convincing in their partnership endeavors. An analyst on this topic pointed out that "Russia is more than willing to tolerate instability and economic weakness in the neighboring countries, assuming they are accompanied by an increase in Russian influence. In fact, Russia consciously contributes to the rising instability and deterioration of the economic situation in some, if not all, of these countries". (Stewart, S. (2014).

For Central Asia, we do not find particular aspects in Russia's foreign policy. To the issues already mentioned, in the case of these states, one can add the argument that, after the disintegration of the USSR, within their borders there were several millions of Russians whom the mother country feels to take care of. The Russian authorities are constantly giving assurances that they do not intend to use this argument to initiate actions to be considered threatening by the states in the region. However, the reality shows that, on more and more occasions, this argument is invoked or used to obtain certain concessions or to determine certain forms of partnership. It can be illustrated with the case of Kazakhstan, when this argument began to be invoked as early as 2006. Moreover, certain statements by Russian leaders such as the proposal to create a new state called „Novorossiya,, on the eastern border of Ukraine, need not be to be treated with 
indifference, being considered pure exercises of diplomatic rhetoric, but it is compulsory to take them seriously and prepared appropriate reactions to them.

\section{Concluding remarks}

The most frequent used modalities in which the decision-makers in Russia operate are an interesting combination between the traditional tools, applied since the time of the Tsarist Empire, others are newer and considered adequate to the geo-political and geo-economic realities of the beginning of the new century (energy weapon and virtual space). The handling of interethnic conflicts and the activation of "frozen conflicts" have been used in practically all cases. In other cases, the cyber instrumentation or even direct military intervention was insisted upon.

The ingenuity of the Russian authorities regarding the combination of means used in various situations and their degree of sophistication cannot be overlooked. It is also important to point out that the mix of action instruments was not a short-term one, but expresses a robust continuity and a synergistic alignment with the strategic objectives of the country's foreign policy. This attitude fully underlines the focus of the steps at the highest level of the political decision and the pursuit as an essential target of the foreign policy of restoring the country's role of high military-strategic and, as far as possible, economic power.

The media assault of the Russian authorities was not limited to the government or civil society level in the former Soviet space, but advanced to the Western democratic world. Very strong public relations campaigns had political decision makers or opinion vectors in the Western world at their center. To these were gradually added influential journalists, renowned scientific researchers, prominent art and culture.

\section{References}

Ashcroft, Bill; Griffiths, Garret and Tiffin Helen - Post-colonial studies. The key concepts. Second Edition, Routledge. Taylor and Frances Group. London 2000.

Carmen, Amelia and Gayoso, Descalzi (2013). Russian Hegemony in the CIS Region: An Examination of Russian Influence and of Variation in Consent and Dissent by CIS States to Regional Hierarchy. Doctoral Thesis submitted to the Department of International Relations, London School of Economics, pp. 52-85, 124-160.

Darian-Smith, Eve (2015). Postcolonial Law. In International Encyclopedia of the Social \& Behavioral Sciences (Second Edition).

Etkind, Alexander (2011). Internal Colonization, Russia`s Imperial Experience. London. Polity Press.

Etkind Alexander - How Russia 'Colonized Itself . International Journal for History, Culture and Modernity. Vol 3. No 2. 2015.

Gayatri, Spivak (1988). Can the Subaltern Speak? In Cary Nelson and Lawrence Grossberg (eds.) Marxism and the Interpretation of Culture. London: Macmillan, 1988.

Hale, H. (2005). Regime Cycles: Democracy, Autocracy and Revolution in Post-soviet Eurasia. World Politics, No 58, 2005, pp. 133-165

Mankoff, Jeffrey (2013). Eurasian Integration: The Next Stage. Central Asia Policy Brief, Elliott School of International Affairs, George Washington University, p. 1.

Medvedev, Dimitri (2008). Interview to Television Chanel One, NTV, August 31.

Moiseev, N.N. (1999). Rossia na pereputie. Sotsialno-gumanitarnye znaniia, No. 4, pp. 173-174. Northrop, Douglas (2012). A Companion to World History. West Sussex (UK): Wiley Blackwell.

Patrick Williams, P and Chrisman L. (eds.), Colonial Discourse and Post-Colonial Theory: A Reader (Hemel Hempstead, UK: Harvester Wheatsheaf, 1993. 
Stalin, I.V. (1942). The Policy of the Soviet Government on the national Question in Russia. Pravda. October 10. 1920. Joseph Stalin, Marxism and the National Question: Selected Writings and Speeches, New York: International Publishers, p. 77.

Starr, Frederick; Cornell Svante (ed.) (2014). Putin's Grand Strategy: The Eurasian Union and Its Discontents. Central Asia-Caucasus Institute \& Silk Road Studies Program.

Stewart, Susan (2014). The EU, Russia and Less Common Neighbourhood. SWP Comments. Stiftung Wissenschaft Und Politik, January.

PICBE $\mid 473$

*** Rossiyskhaya Gazeta. Moskow, September 23, 1995.

***, Strategiia Razvitiia Otnoshenii Rossiskoi Federatsii s Evropeiskim Soiuzom na Srednerochnuiu Perspectivu (2000-2010), Diplomatickeschii Vestnik, November 1999. www.In.mis.ru/website/dip_vest.nsf items 1.1.,1.6, and 1.8.2000, cited in Hannes Adomeit and Heidi Reisinger, Russia's Role in Post-Soviet Territory: Decline of Military Power and Political Influence, Norwegian Institute for Defense Studies, Forsvarstudier No. 4, 2002, p. 5. 